\title{
LANDFILL MINING APPLICATIONS IN THE LOMBARDY REGION
}

\author{
Silvia Cappa * \\ Regional Government of Lombardia, Piazza Città di Lombardia 1, Milano 20124, Italy
}

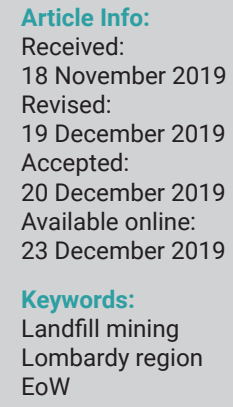

\begin{abstract}
Landfill Mining is still today a rare activity in Italy, certainly due to the high costs of realization, the difficulty of finding outlets for the waste extracted and its quality. An important contribution is given by unclear administrative procedure in the absence of a regulatory framework that contemplates this case. However, something is moving: in the last year in the Lombardy Region two interventions have been approved and implemented and a third is at the Environmental Impact Assessment procedure. All of them are aimed at the recovery of areas and have in common a limited extension and depth, an absence of environmental contamination and focus on a type of waste easy to recover/dispose of.
\end{abstract}

\section{INTRODUCTION}

Landfill is the last option in the list of priority that the European Commission defined for waste management; the landfilled products in fact cannot be used and can cause pollution, and the area is definitely compromised. In Europe it is estimated that there are more than 500.000 landfills, closed or in operation (source Eurelco - European Enhanced landfill mining consortium, 2018), that could be a potential risk for the environment and human health and contain a large quantity of metals, minerals or fuels to recover.

The application of Landfill Mining (LFM) could facilitate a different use of the site and could convert waste to materials to make new products or to generate energy.

Here is a summary of goals that can be achieved with a LFM project:

- reduction or zeroing of environmental impact of old landfills;

- material recovery, with an economic return;

- energy production from waste with a high calorific value and that cannot be recovered as material;

- availability of the landfill area for different use;

- availability of the landfill volume for non-recoverable waste.

LFM is perfectly compliant with the principles of Circular Economy, because it allows the material recovery and the utilisation of the site for other purposes. However, Landfill Mining has, till now, few applications in Italy, why? The first reason is probably the high cost of intervention, especially in case of contamination of ground or water, compared to the value of recovered materials. The high cost is due to the difficulties of operating it safely in the landfill area and the lack of available technologies to recover the material from the landfilled waste.

An important role is also played by unclear regulations for this sort of activities and uncertainty on the permitting procedures that discourage investments. The European and Italian laws do not regulate this kind of activity, that can be considered as an activity of soil remediation or as waste management, so it is difficult to define the correct administrative procedures to allow it.

In the Italian legislation, the definition of LFM doesn't exist yet, even if we have already some examples. In 2009 Lombardy Region defined LFM as an "innovative" activity "finalised to recover materials and/or areas and to reuse landfills only for residual waste resulting from recovery activities". Taking advantage of the submission of four landfill mining projects, Lombardy Region created a specific framework for the assessment of LFM projects that considers different cases.

In our opinion LFM should be authorised under the waste management legislation rather than under the soil remediation, even in case of contamination of environmental matrices.

(every time the landfill has been approved was under national law n. 152/2006 - Testo Unico Ambientale - and n. 36/2003 - Landfills).

\section{EXAMPLES OF APPLICATION OF LFM IN THE LOMBARDY REGION}

In the last few years in the Lombardy Region four experiences of LFM application have been proposed; this shows 
the interest of the waste management market in LFM and its opportunities.

Two out of four are not approved yet and concern waste from steelwork, the others two are completed and a lot of information on the way of realization is available.

All these examples have in common the goal of recovering the area devoted to the landfill however, only in the case of aggregate waste they have a plan for the material recovery.

A description of Lombardian LFM application is in the following.

\subsection{Mella 2000}

This is a case of an old landfill, realised at the end of '70 and closed in 1997, near a watercourse, in an industrial area; the landfilled waste is inert residual from steel production. Landfill has not waterproofing system, nor a system for collecting and removal leachate and biogas. Investigation did not show contamination of environmental matrices.

The goal of the LFM activity is recovering the area to realise a new building (comparto $\mathrm{D}$ ) to complete the commercial district "Mella 2000". Steel waste will end up to another landfill, construction and demolition waste will be used - when possible - for the re-profiling of the area. The propriety of the area is private. The landfill area is of about $26.400 \mathrm{~m}^{2}$ and the removal project excludes a part of 900 $\mathrm{m} 2$, where a high voltage power line is located.

The campaign plan, following drilling in August 2008, November 2011 and May 2013, denotes the presence of waste belonging to the category of steelworks, in some cases mixed with fragments of bricks and iron. Rare mud horizons have been detected in some cores. In any case, the results of the analyses carried out on the waste samples in the points investigated have found that the material deposited there is definitely to be classified in the steelworks family. Waste are landfilled from a minimum depth of about 4 meters to a maximum depth of 8 meters (Figure 1).

With regard to the delimitation of removal operations, it has been taken into account that the area of intervention is characterized by multiple presences of sub-service lines (traced high voltage power line Terna; high-pressure meth-

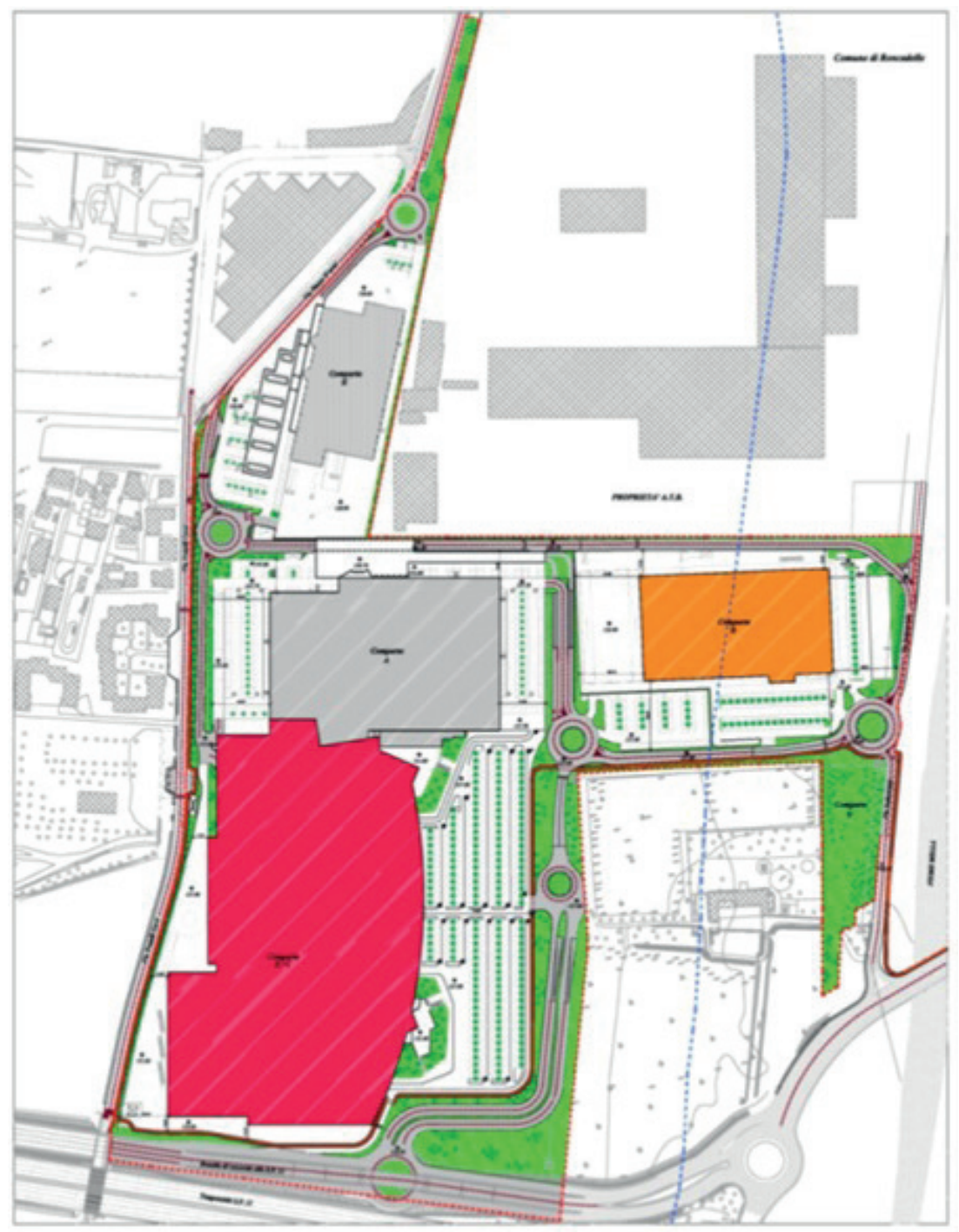

FIGURE 1: The "Mella 2000" project * 
ane gas pipeline SNAM; agricultural irrigation channel. The Terna line is not susceptible to translation, as it has recently been laid, and given the complexity and delicacy of the work. The presence of such infrastructure obliges compliance with a range of $3 \mathrm{~m}$ from the axis of the cables, within which no work can be performed. In addition, excavations or any supporting bulkheads must be maintained at a proper distance to ensure the safety and stability of the infrastructure, profiling the ground with stable escarpments.

For this reason, the removal project, on the east side, excludes the portion occupied by Terna and its respect band. On the other hand, the SNAM pipeline, which is also burdened by a respect band of $3 \mathrm{~m}$ from the axis of the pipeline, is expected to be translated. To relocate the methane gas pipeline, it is convenient to locate the latter alongside the Terna power grid, thus allowing the overlap of the respective respect bands and minimizing the dimensions. The hypothesized solution guarantees, in fact, to maximize the extent of the waste removal intervention area (actual excavation area is equal to approximately $24.500 \mathrm{sqm}$ ). The solution proposed in the project makes it possible to use the basement wall, supporting the underground surfaces of the future property that will be realized on the sector, thus profiling the ground with stable escarpment. The agricultural irrigation channel will be placed underground. The boundary of waste removal along the east side is therefore identified with the basement wall of the future property that will be built on the area, while, along the north side, the limit is dictated by the existing road, and by the foot grading along the west and south sides.

On the portions not affected by the removal, a capping will be made with the same characteristics for the safety of the escarpment of the landfill front.

This capping will therefore be made by a $30 \mathrm{~cm}$ thick layer of clay and a $30 \mathrm{~cm}$ draining layer (as a replacement for the layer of vegetable soil equal to $30 \mathrm{~cm}$ ). Prior to the removal of waste, the entire area will be divided into two lots: lot 1 will coincide with the west portion of the area and Lot 2 with the eastern portion of the area. The removal of waste will begin from Lot 1 , the steps that will be carried out are listed below:

- characterization of the material (one per mesh);

- waste removal and loading on vehicles without inter-

mediate storage;

sending to a suitable disposal center;

certification of the excavation bottom plan.

Once the waste removal is completed in Lot 1 , it will be carried out in Batch 2, in the same manner as the first batch.

In consideration that waste will be sent to disposal in another landfill, according to Directive 2008/98/EC, table 1 , annex 1, we decided to assign the operation "D13 - Blending or mixing prior to submission to any of the operations numbered D1 to D12"; this determined the need of an environmental impact assessment (EIA). The realisation of the mall also needed an EIA, so the two assessments were considered in an overall procedure that it is not already completed (Figure 2, Table 1).

\subsection{Railroad Brescia - Verona}

At the moment this project is not formalized yet, but it will be before the end of 2019 .

Available data is limited but this is an interesting case because the LFM activity is key to the realisation of a highspeed railroad and it includes only the removal of landfilled waste along the railway line (about $50.000 \mathrm{~m}^{3}$ ). The dump was in operation from 1987 to 2009 , regularly authorised. LFM will concern more or less $50 \%$ of the total volume of landfill. The portions not affected by the removal will be

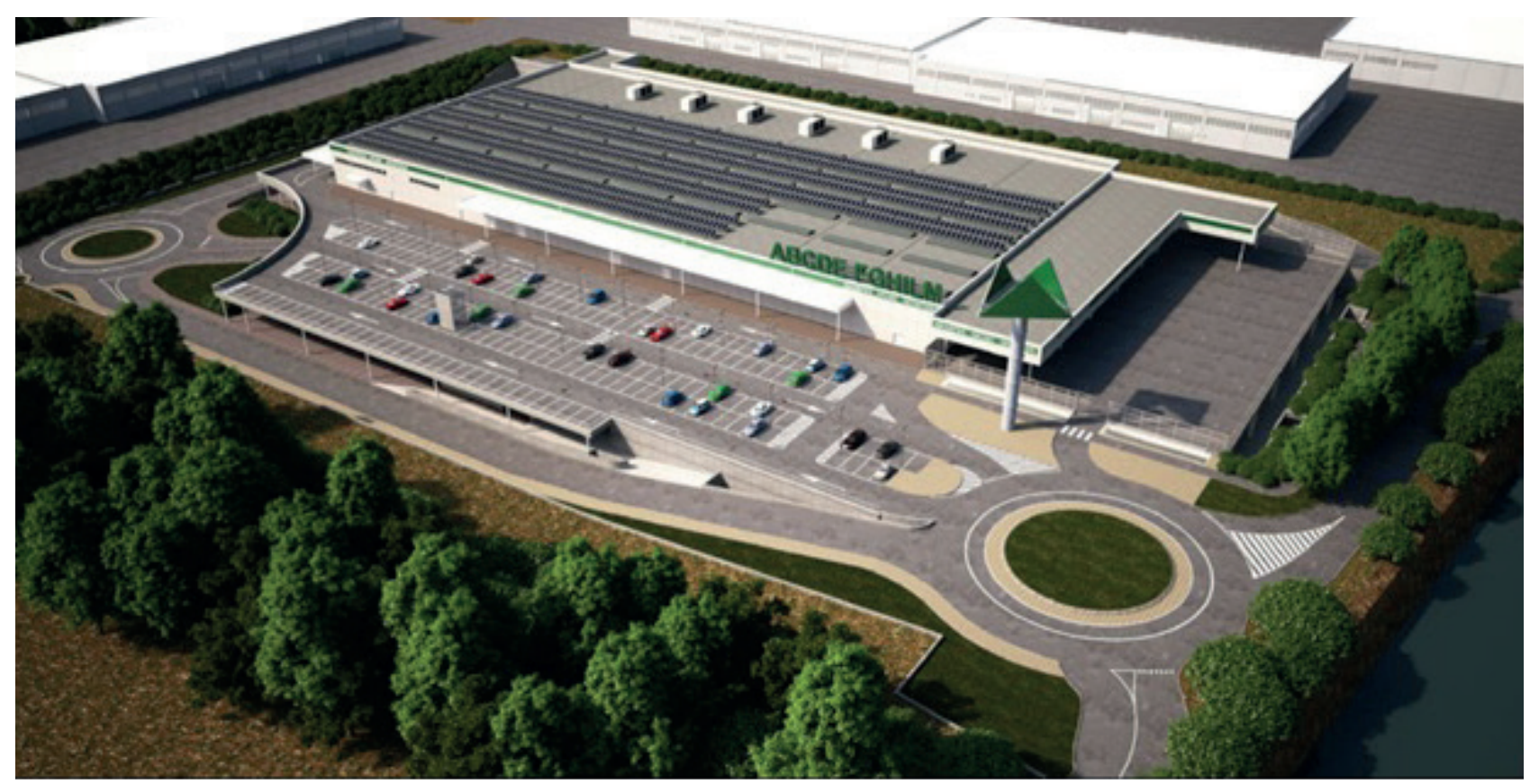

FIGURE 2: Rendering of the future configuration. 
TABLE 1: Characteristics of the landfill mining activity.

\begin{tabular}{l|l:l}
\hline Amount of removed waste & $150.000 \mathrm{~m}^{3}$ & Partial removal \\
\hdashline EWC European waste code & 100202 & Untreated slag \\
\hdashline Recovery Operations & D13 & Blending or mixing prior to submission to any of the operations numbered D1 to D12 \\
\hdashline Days of work & 110 & 0.5 \\
\hdashline Treated amount per day & $2570 \mathrm{t}$ & 43.6 \\
\hline
\end{tabular}

TABLE 2: Characteristics of the landfill mining activity.

\begin{tabular}{l|l:l}
\hline Amount of removed waste & $50.000 \mathrm{~m}^{3}$ & Partial removal \\
\hdashline EWC European waste code & 100202 & Untreated slag \\
\hdashline Recovery Operations & D13 & Blending or mixing prior to submission to any of the operations numbered D1 to D12 \\
\hline
\end{tabular}

made safe with a barrier of containment poles, $15 \mathrm{~m}$ deep and $120 \mathrm{~m}$ long.

Landfilled waste is slag from steelworks, mixed with other waste, so the recovery cost is too high according to the benefit coming from the sale of products. Furthermore, it is difficult to find a market of this kind of waste; so, it will be sent to another dump.

Environmental investigations carried out in 2014-15 analysed groundwater, upstream and downstream, and soil down and up to waste.

The surveys showed light contamination of soil $(\mathrm{Pb}, \mathrm{Zn}$, $\mathrm{Cr}$, hydrocarbons) and a new campaign will be organised in the next few months.

The Ministry of Transport is responsible to authorise the permit of the railroad, while the LFM activity is a Lombardy Region's responsibility (Table 2).

\subsection{Municipality of Sermide}

Landfill is located far from urban area, near a municipal waste collecting plant. The Municipality is the owner of the plant and of the landfill and needs to increase the waste collecting area (Figure 3 and Figure 4).

In operation since 1996 to 2002, the landfill was divided in two parts: $7000 \mathrm{~m}^{3}$ of inert waste have been landfilled in the part $A$, and $740 \mathrm{~m}^{3}$ in the part $B$. The maximum thickness is $4.5 \mathrm{~m}$, there is no waterproofing system, nor a system for collecting and removal leachate and biogas. In 2015 an environmental investigation analysed ground water, upstream and downstream, and ground down and up to waste.

Investigation did not show contamination of environmental matrices and brought out that waste was for $80 \%$ gravel and crushed rocks with $20 \%$ of plastics and inert waste (construction and demolition waste).

The project includes a shredder mobile plant: after the separation of different waste, plastic and construction and demolition waste will be sent to recovery plants, gravel and crushed rocks will be shredded and used in site for the re-profiling of the area or sent to recovery plants (Figure 5).

\subsubsection{Project phases}

There are 4 sampling points to be performed on the ground below the mounds, 3 of which are below Cumulus $A$ and one below Cumulus B. Three stages of work (phases) will be made for pile $A$ and 1 for pile $B$. For each stage, the work will be organized with the following steps:

- excavation of the material;

- visual verification of the presence of foreign coarse fractions of a non-inert nature (plastics, wood, glass, metals, etc.); if found, these will be removed manually

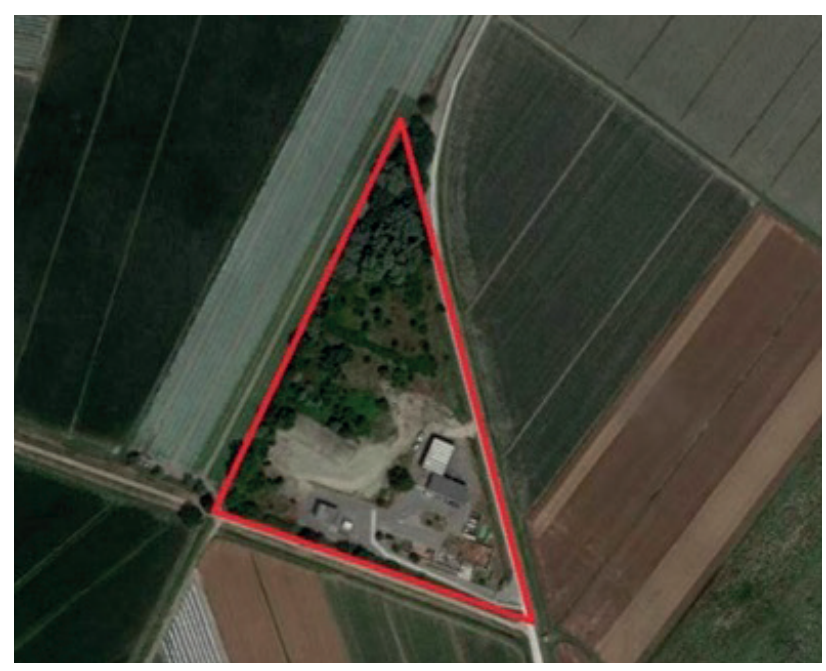

FIGURE 3: View of the dump and the plant.

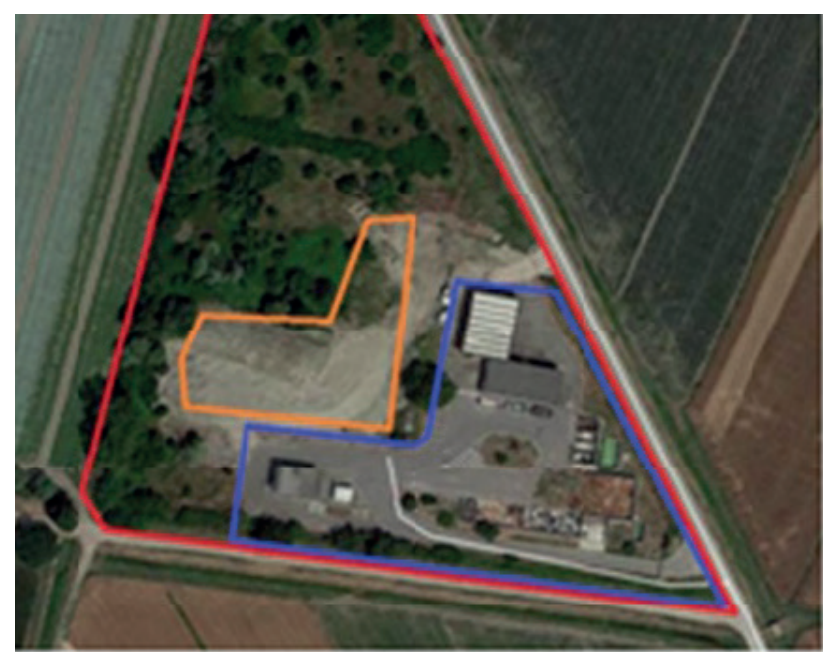

FIGURE 4: Landfill (in orange) and municipal collecting plant (in blue) 


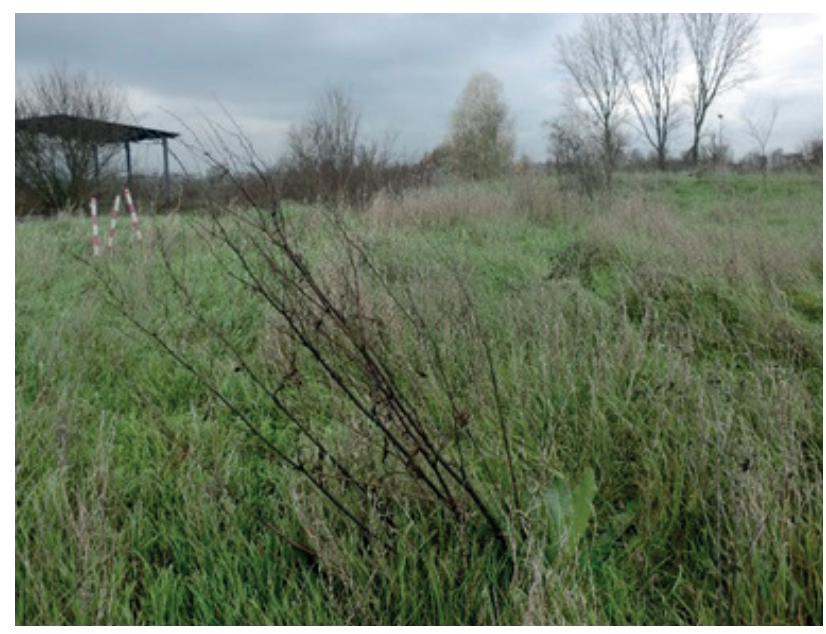

FIGURE 5: The landfill area before LFM intervention.

by the operators or with the assistance of a supplied mechanical tools (excavator bucket); this waste will then be identified and managed under a temporary storage regime, with storage in heaps and delivered to authorized facilities for subsequent recovery/disposal; - storage waiting for an optimal quantity for processing; - mechanical treatment by crushing in a plant with a mobile crusher;

- sampling of the material obtained from the treatment for compliance verification (this check will be performed every $3,000 \mathrm{~m}^{3}$ of material produced);

- excavation of trench in the natural soil at the bottom, up to a depth of 1.5 meters below ground level and collection of 1 representative sample to be analyzed;

- once the ground has been declared free of contamination and the material leaving the treatment has been deemed compliant, the material will be laid out in the area of the lot considered. Excavation and internal handling of the material will be carried out by mechanical shovel/hydraulic excavator.

The shredder mobile plant will perform the volumetric reduction of large brown elements and it will allow the homogenization between the different types of inert materials and the separation of the pieces of iron. The machine is equipped with a powder control system which uses nozzle nebulizers which are positioned at the mouth and at the discharge of the mill; these nebulizers deposit very fine water particles on the material. From the process described above, a recycled material is obtained, free of iron parts and other non-inert fractions, of granulometry 0-40 $\mathrm{mm}$ : this recycled material will then have to be verified to ascertain its qualification of end of waste. As there is a lack of information about its nature and origin, landfilled waste will be classified with EWC 1709 04, mixed construction and demolition waste; in any case it is of solid, non-pulverulent, inert waste (presumably concrete, bricks, tiles, stones, plasters, mortars, and the like) not odorous and non-putrescible with possible amounts of other materials such as wood, plastic, glass, rubber, etc. (Figure 6, 7 and 8).

Recovery Operations is R5 "Recycling/reclamation of other inorganic materials" for 13.800 t of non-hazardous waste (Table 3).

\subsection{Erba}

This case considers a dump for construction and demolition waste, for a total volume of $38.000 \mathrm{~m}^{3}$, managed by a public administration in the ' 90 , regularly authorised by Lombardy Region and monitored by Provincia di Como. The project includes the transformation of an area of $57.000 \mathrm{~m}^{2}$ in industrial/commercial buildings (Figure 9 and Figure 10).

In 2012-2014 the private owner of the area executed an environmental investigation; the investigation concerned an area used as a landfill $\left(23.000 \mathrm{~m}^{2}\right)$ and another green portion next to it $\left(35.000 \mathrm{~m}^{2}\right)$. The project includes the transformation of the entire zone in industrial/commercial buildings.

The green area has never been used, the other portion was a gravel pit in the '60, a motocross track from 1970 to 1989, a landfill from 1993 to 1996. The landfill area is in banking, on the contrary the other portion is in the depression; this means that a morphologic rearrangement is needed.

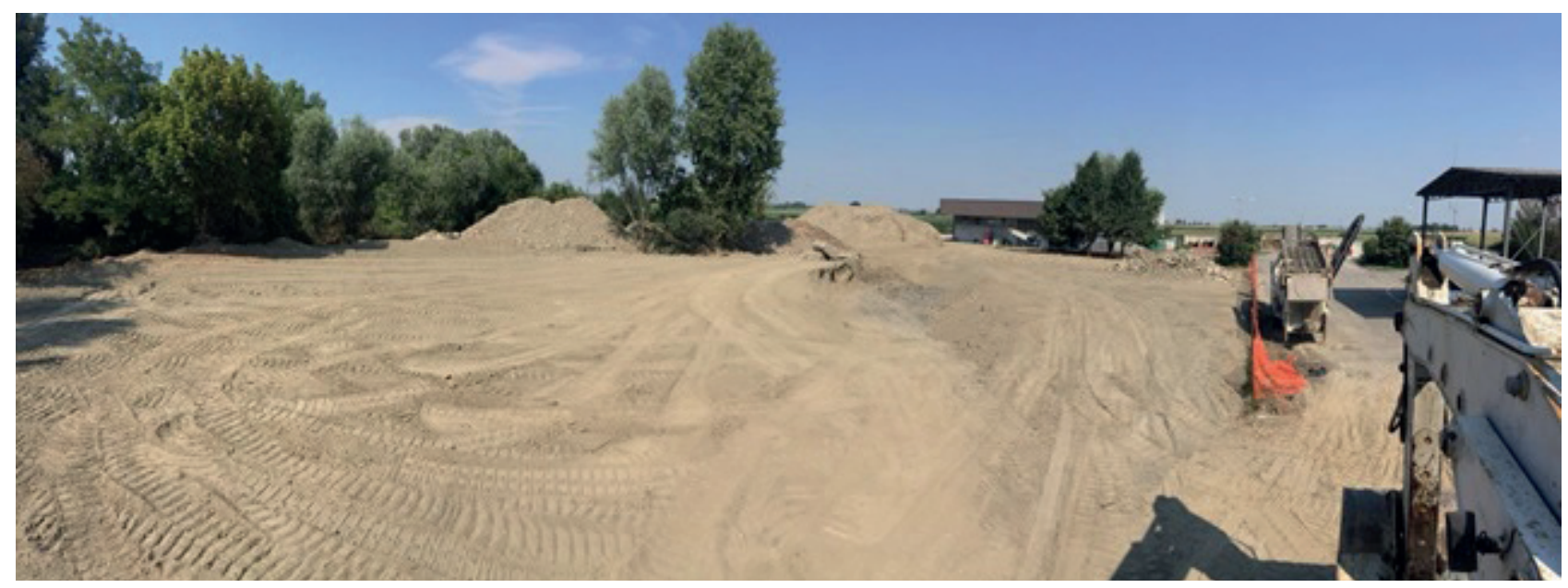

FIGURE 6: The landfill area before LFM intervention. 


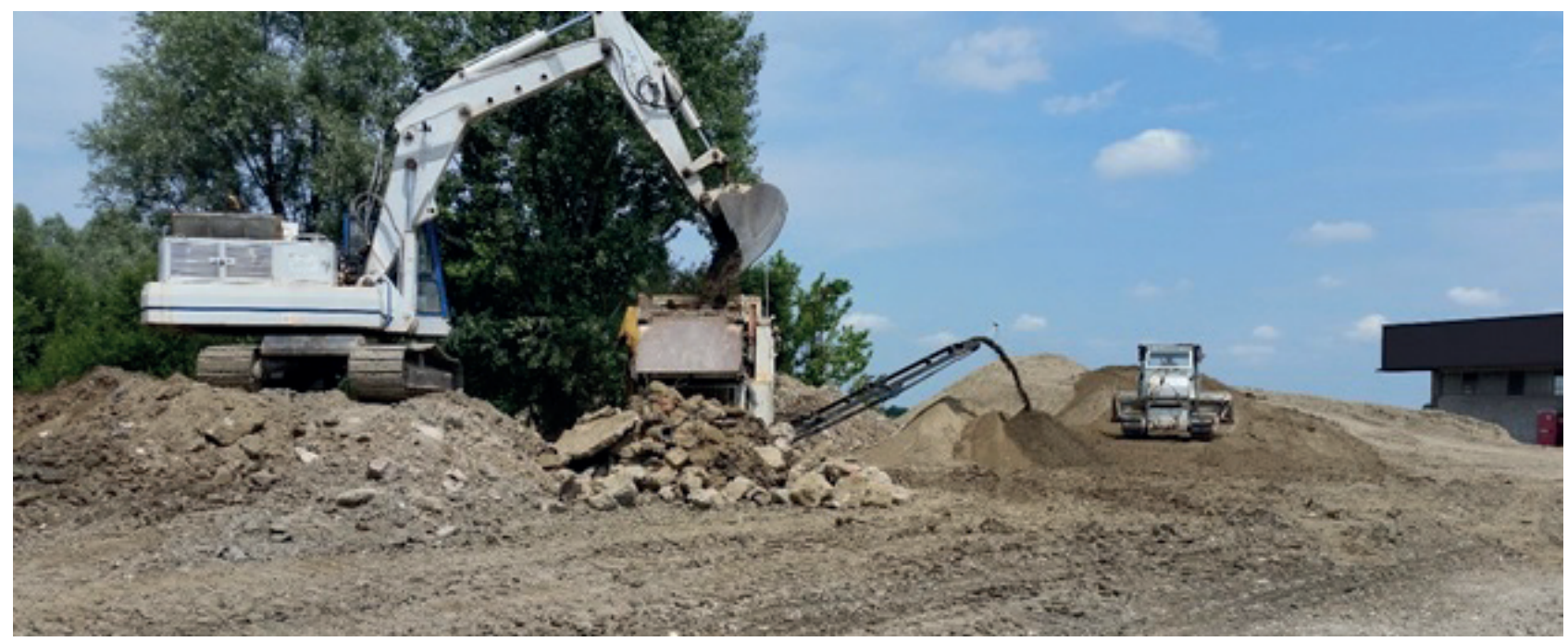

FIGURE 7: The shredder and the different grounds sorted.

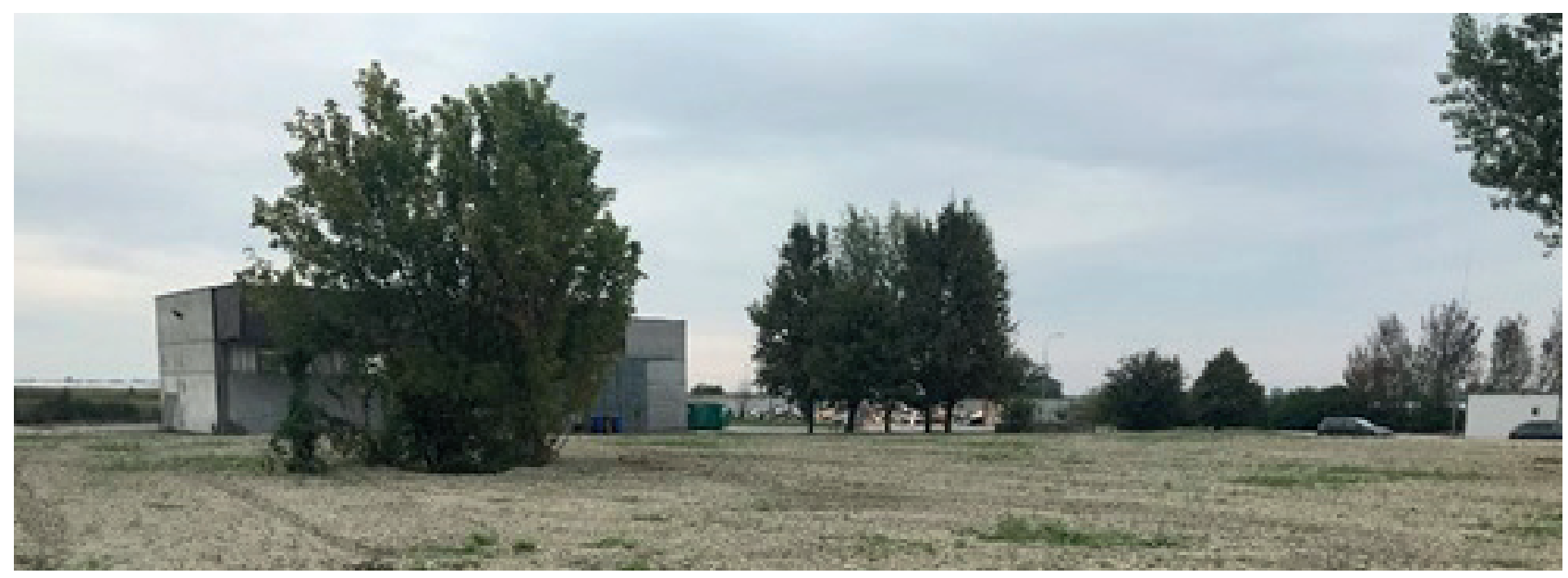

FIGURE 8: The area at the end of LFM

The Investigations which ended in 2014, concerned:

- cartographic, documental and historical survey;

- geophysics survey, that showed 2 gas pipelines and an old water pipeline;

- hydrogeological survey;

- plano-altimetric test;

- geognostic survey.

This led to a conceptual model of the area.

The Investigations also brought to the verification of the characteristics and quality of:

- the groundwater, downstream and upstream;

- ground at the bottom and around the landfill;

- waste and capping.

No contamination of environmental matrices was found (Figure 11).

The perimeter of the area of intervention is about $24.000 \mathrm{~m}^{2}$, the volume of landfilled waste $38.000 \mathrm{~m}^{3}$ with a height, from the ground level, of $4,3 \mathrm{~m}$ maximum and 2,8

TABLE 3: Characteristics of the landfill mining activity.

\begin{tabular}{|c|c|c|}
\hline Amount of waste & $7730 \mathrm{~m}^{3} ; 13.800 \mathrm{t}$ & Complete removal \\
\hline EWC European waste code & 170904 & $\begin{array}{l}\text { Mixed construction and demolition waste other than those mentioned in } 1709 \text { 01, } 1709 \\
02 \text { and } 170903\end{array}$ \\
\hline Recovery Operations & R5 & Recycling/reclamation of other inorganic materials \\
\hline Days of work & 75 & 0.5 \\
\hline Treated amount per day & $940 \mathrm{~m}^{3} ; 1680 \mathrm{t}$ & 43.6 \\
\hline Estimated recovered material & $9000 t$ & \\
\hline
\end{tabular}




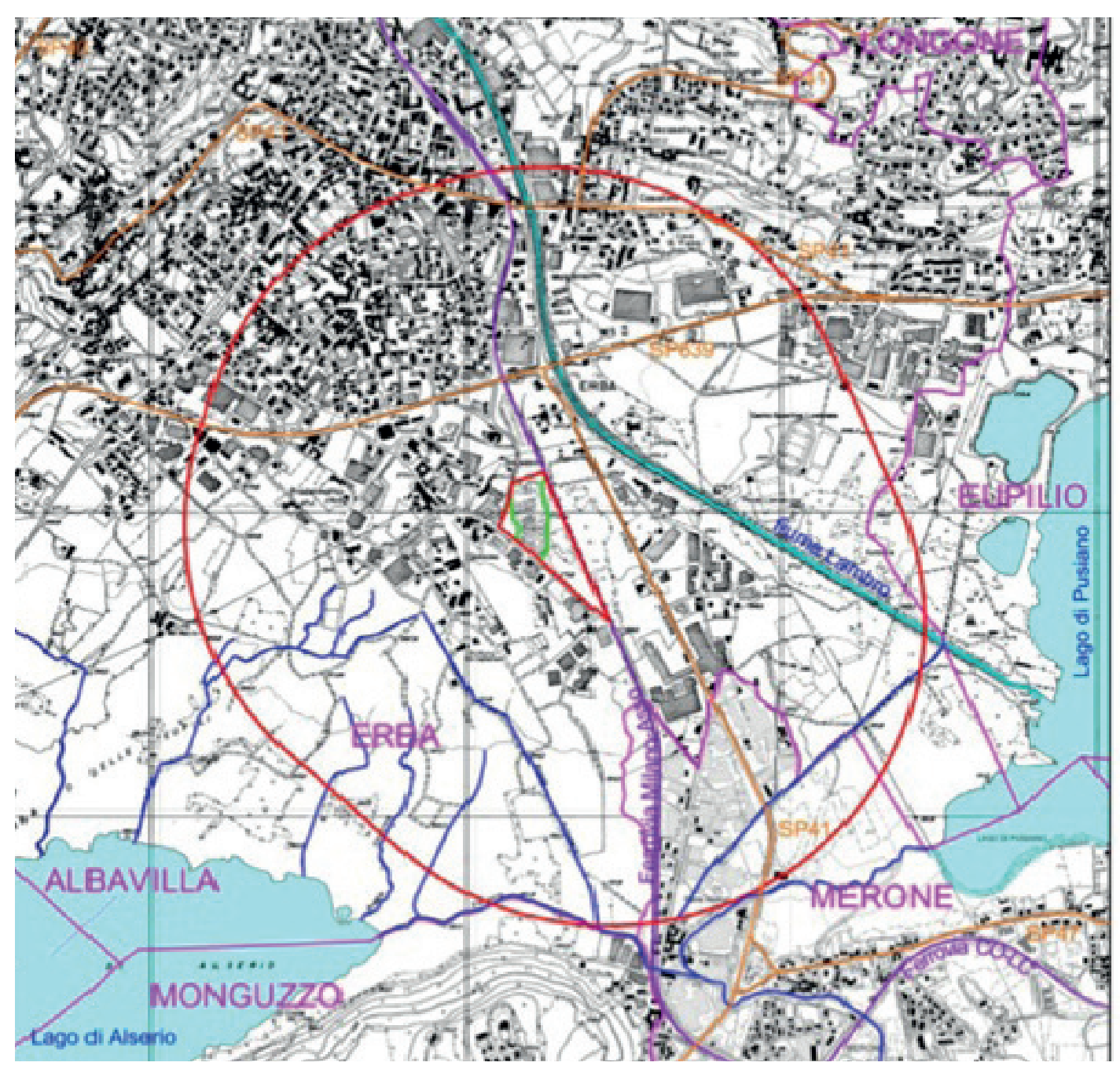

FIGURE 9: Localisation of intervention (in green the landfill)

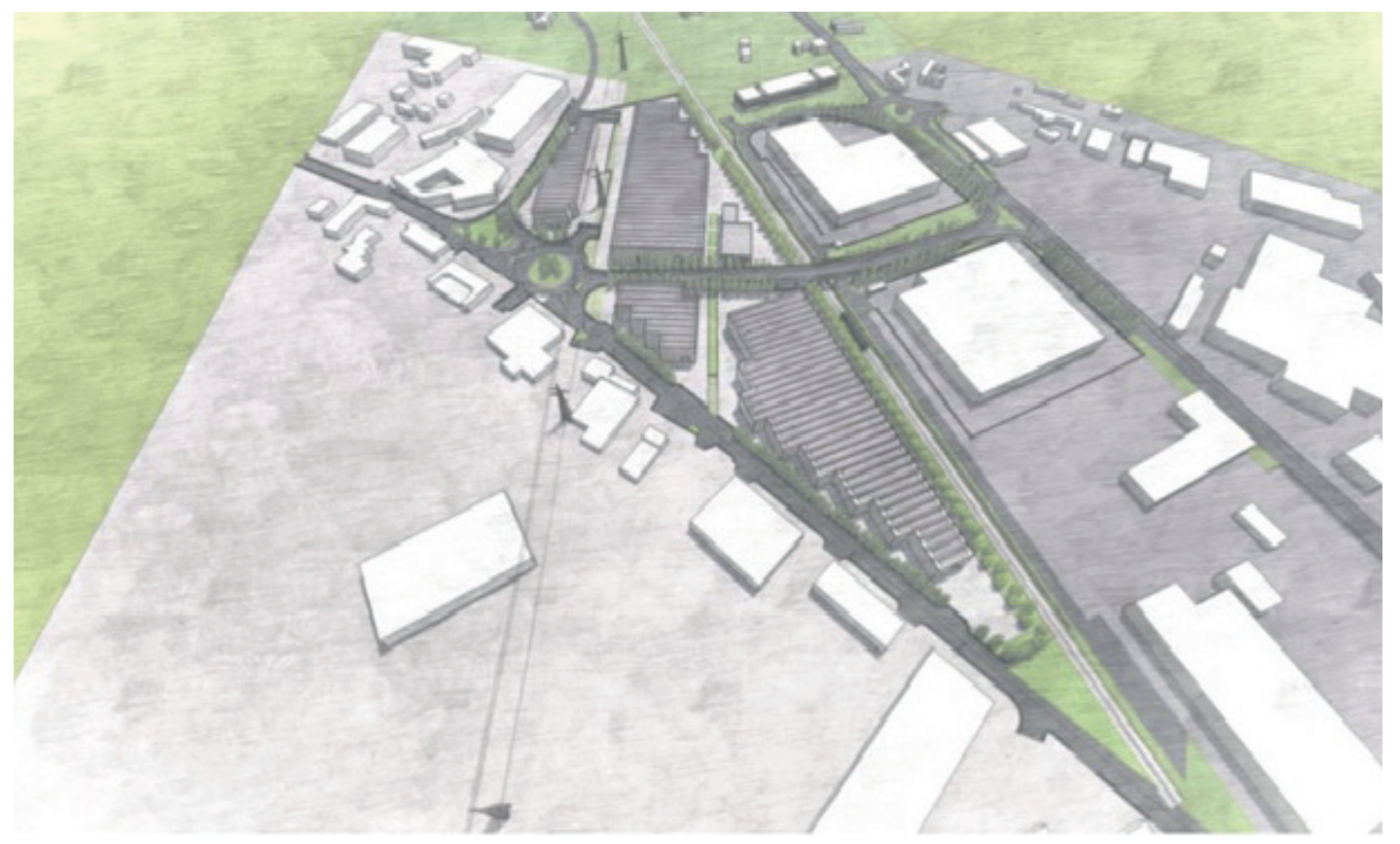

FIGURE 10: Rendering of the future configuration. 


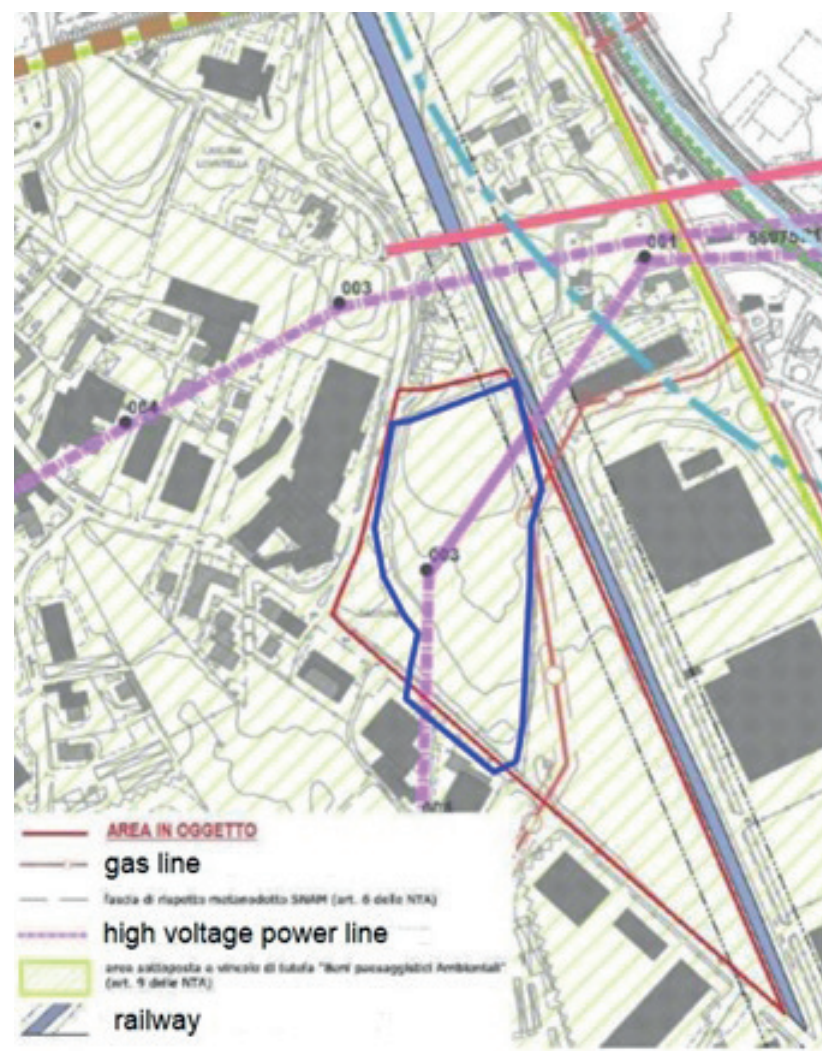

FIGURE 11: The area of intervention (in red), the landfill (in blue) and the facilities.

of average. The minimum quota of waste is at $267,00 \mathrm{~m}$ a.s.I. and the groundwater is at average $265,5 \mathrm{~m}$ a.s.I., with a seasonal fluctuation of $+/-3.5 \mathrm{~m}$. Before the disposal of waste, the ground has been regularised and the slice of depression have been covered with $30 \mathrm{~cm}$ of clay.

The capping is realised in $30 \mathrm{~cm}$ of clay and $50 / 70 \mathrm{~cm}$ of topsoil.

Characteristic of landfilled waste found in management documents were verified in site: the total amount of waste is construction and demolition materials.

The project includes a shredder mobile plant to decrease dimensions of waste and leads to the use of materials for the re-profiling of the area.

The Recovery Operation is R5 "Recycling/reclamation of other inorganic materials" for 30.000 t of non-hazardous waste, the amount needed for the morphological reconfiguration; $8.000 \mathrm{t}$ will be sent off-site.
The treatment of 38.000 t needs an environmental impact assessment, which is responsibility of the Lombardy Region (Table 4).

The analysis of available time and space brought to the solution of dividing the area of intervention in portions; waste recovered by the shredder will be used for filling depressed areas. During these activities the mobile plants will move in 3 different positions.

\subsubsection{Project phases}

- removal of the cover layer $(50 / 70 \mathrm{~cm}$ of cultivated soil and $30 \mathrm{~cm}$ of clay) of the landfill and reuse of a part for filling portions of natural soil area. Before the excavation operations start, a chemical - physical analysis will be performed by taking samples of both the culture soil and the clay layer; this analysis is aimed at providing the characteristics of these materials for a proper delivery to a different site for a portion and for the reutilisation project of the remaining portion. The recovered material will be used for the morphological reconfiguration of the entire area of transformation, starting from the depressed zones, leveling the entire area from the existing road surface.

Once the installation of the construction site and the displacement of the site portions of the "natural soil" area, FASE 0 will be completed with the realization of a new piezometer "PZM-2018" and contextual sealing of the piezometer "PZM-1994" at the centre of the body of the landfill (which dates back to 1994): such actions are needed because subsequent landing activities will necessarily result in the demolition of the existing PZM function. The piezometer made during the Preliminary Environmental Survey further south in 2013 (PZV-2013) will instead provide representative samples of the first groundwater downstream of the perimeter of the landfill, the monitoring will be on a monthly basis for the entire duration of the recovery activities;

- removal and recovery of the inert material that constitutes the body of the landfill and reuse of the recycled aggregate obtained to fill portions of natural soil area. Before the on-site recovery treatment, chemical-physical analyses of waste will be carried out, and at the end of the mechanical recovery process (screening and crushing), the material will be further analyzed in batches from a product and chemical-physical point of view in order to qualify the recycled product aggregate that, once certified, will be re-used to continue

TABLE 4: Characteristics of the landfill mining activity.

\begin{tabular}{|c|c|c|}
\hline Amount of waste & $38.000 \mathrm{~m}^{3} ; 68.400 \mathrm{t}$ & Complete removal \\
\hline EWC European waste code & 170904 & $\begin{array}{l}\text { Mixed construction and demolition waste other than those mentioned in } 170901,17 \\
0902 \text { and } 170903\end{array}$ \\
\hline Recovery Operations & R5 & Recycling/reclamation of other inorganic materials \\
\hline Days of work & 63 & 0.5 \\
\hline Treated amount per day & $1250 \mathrm{~m}^{3} ; 2250 \mathrm{t}$ maximum & 43.6 \\
\hline \multicolumn{3}{|l|}{$475 \mathrm{~m}^{3} ; 855 \mathrm{t}$ average } \\
\hline Estimated recovered material & $30.000 \mathrm{~m}^{3}$ & \\
\hline
\end{tabular}


morphological reconfiguration of the entire area of intervention. Recycled inert aggregates, will be obtained from the on-site processing operations, this will need to be compliant with Italian law (Annex C4 of the Circular $\mathrm{UL} / 2005 / 5205$, which is related to the production of a "recycled aggregate for the realization of environmental recoveries and fills"). Especially a leaching test will verify the grain size and the composition of the material, its fractions and its chemical compatibility;

- chemical and physical analysis on natural soil under the landfill and start of the morphological reconfiguration of the ex-landfill portion by re-using the recycled aggregate obtained from the recovery cycle. An Environmental survey of soils below ex-landfill (bottom check) is necessary in order to confirm non-contamination, thus certifying the recovery of the area which was until then a former landfill of inerts. In the "natural soil" area there is a gas pipeline owned by SNAM's gas network; the pipe trunk, placed at a depth of about 1.5 $\mathrm{m}$ from the campaign plan, is contained and protected by a concrete artifact that allows operation of the area with these constraints: the possibility of work being undertaken at no less than $2 \mathrm{~m}$ distance from piles and fixed installations.

The morphological reconfiguration project planned to achieve a level of - $50 \mathrm{~cm}$ from the finished floor; this will be achieved using $1 / 3$ of the recovered materials (about $10,000 \mathrm{mc}$ of the $30,000 \mathrm{mc}$ produced), some of this material will also be used for the construction of part of the road in the new viability design. The project will continue with the spread and compaction of $30 / 40 \mathrm{~cm}$ layers of the aggregate recycled with the use of mechanical shovel to be followed by rolling operations and the testing of the compaction with daily density tests and load tests with plate at the end of each layer. Based on the results of these tests and on the basis of the size and geological records of the material, an assessment will verify the need to improve the material's mechanical properties of the soil by mixing the soil with binders (lime and/or cement) - Figure 12.

\section{CONCLUSIONS}

The experiences described in this article show an interest versus LFM in case of interventions characterised by:

- limited extension and volumes;

- non-hazardous waste;

- possibility to convert landfill area in other uses.

The interest for the recovering of these areas is in part due to the limitation of using virgin soil established by Lombardy Region in 2014 (regional law n. 31); this added an extra cost for edification in agricultural area and a reduction for interventions in degraded areas.

Sometimes - as in the example of point 2.2 - LFM is not a choice, but it is a need to complete a project (the construction of new infrastructure or new urban complex). In this situation the strategic value of infrastructure is so high to justify the cost of LFM intervention, even in case of contamination of environmental matrices.

The recovery of materials is, at the moment, limited by the cost, which is too high compared to the value of landfilled waste.

These costs include:

- surveys to define the contest (characteristic and quality of groundwater, soil, waste), often difficult and expensive also because of the old age of landfills;

- activities for ensuring safe excavation;

- treatment (mechanical, chemical, thermal,...);

- disposal of residual waste.

In Italy there is also an additional problem created by the difficulty for the authorities to certificate end of waste (EoW) on a 'case by case' basis without national criteria for evaluation; these have been in the Italian Government's programme since 2006 but they have not been finalised yet except for a few specific kind of waste and processes.

This creates a distrust for EoW with a resulting difficulty in finding a market.

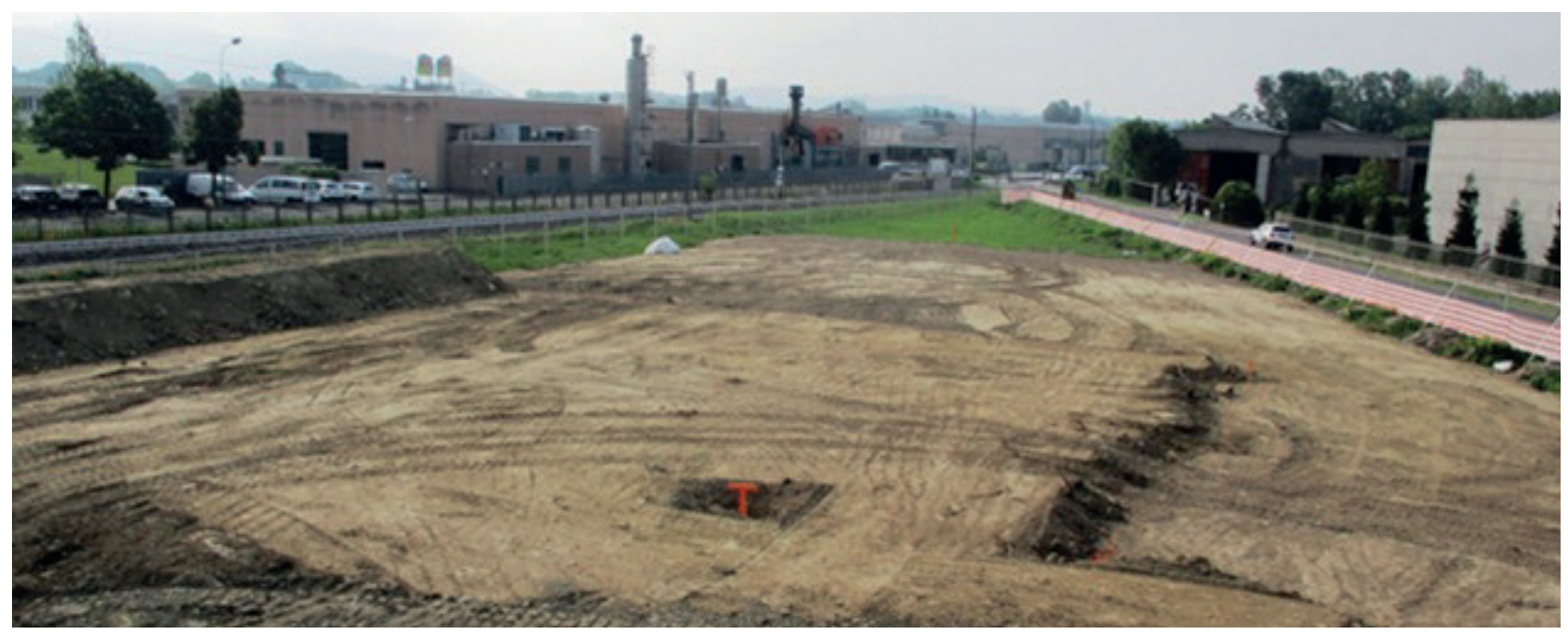

FIGURE 12: The area at the end of LFM. 